\title{
Innovations in Family Practice: Context Matters
}

\author{
Edith A. Lewis ${ }^{1}$
}

\begin{abstract}
In the introduction to this thematic issue, the guest editor provides a model for recognizing the importance of social, political, and historical contexts in family practice. Using illustrations drawn from Michigan's families during the last decade, this introduction outlines how little contemporary family theories reflect the lived realities of contemporary family structures and processes. She encourages family practitioners to be aware of the innovations in interventions present across several disciplines, and to use their own expertise to inform family theories and research.
\end{abstract}

Key Words: Family practice, family therapy, family theory, family policy, social, political, and historical contexts, practice innovations.

${ }^{I}$ Edith A. Lewis, MSW, Ph.D. is Associate Professor, School of Social Work, University of Michigan, 1080 S. University, Ann Arbor, Michigan, 48109-1106. Electronic mail may be sent via the Internet to edithl@umich.edu.

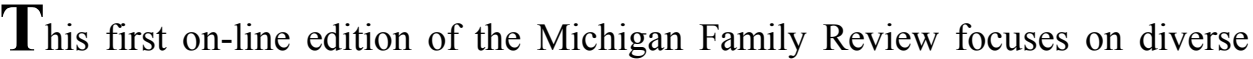
methods of practice with families. We have chosen a framework of family practice rather than family therapy (a) to highlight the importance of social, historical, and political contexts for understanding intra- and extra-familial interactions, including that of the therapeutic alliance; (b) as a way of illuminating the number of disciplines engaged in individual, couple, family and group-oriented family interventions; and (c) to recognize some of the innovative strategies codified during the last two decades to improve the overall well being of families.

Today, Michigan's families face a variety of challenges that were unimaginable even two decades ago. The extent to which these examples are becoming the norm rather than the exception has become apparent in many public and private arenas in the state, as illustrated by the following situations faced by Michigan families during the last ten years: 
- A kindergarten-aged girl shot and killed at school by a classmate. A detailed examination of the case revealed a brother who had informally adopted his sister's children because they had become homeless due to the inadequacy of the mother's income (Danziger, Ananat, \& Browning, 2004). Although this mother took several buses from one community to another daily for employment opportunities in order to meet the requirements of the 1996 PRWORA (Personal Responsibility Work Opportunity Reconciliation Act, which changed welfare "as we knew it") she could not afford to live in the community in which she worked nor could she afford child care for her children.

- Changes in the provision of physical, occupational, and speech therapy by major insurers in the state, limiting reimbursement for combined therapies to 60 over the course of a lifetime. This change has occurred at a time when Michigan's population is aging, and the probability of the need for these services is increasing. The Michigan Brain Injury Association (BIA) has highlighted the need at the state and local levels for ongoing services for those who have sustained brain injuries from vehicular accidents, strokes and aneurysms, and children not wearing protective headgear while riding bicycles (TBI Challenge, 2004). In any of those cases, 60 visits for truly rehabilitative therapy might be completed within the first two months.

- A rural male high school student who entertained a contact in an Internet chat room with his plans to use explosives and weapons to wreak havoc on his Michigan high school. When finally apprehended, it became clear that his father knew about and approved of the cache of weapons his son had been stockpiling. In addition, many of these weapons were procured with the assistance of a nearby neighbor. One of the little known provisions of the PRWORA regulations was the elimination of supportive services to children who were considered to have emotional or behavioral disorders, even if these significantly lowered the probability of their involvement in activities with likeage peers (Kids Count, 2003).

- A chronically mentally ill man who murdered a new graduate social work student in a restroom at a train depot. The public later learned that, although diagnosed as schizophrenic, this man was not taking his medication. Unlike many other CMI adults in this state, this man had a caring extended family system; however, given the closing of so many of our mental hospitals during the last decade coupled with the lack of community based alternative programs, his family could not secure much needed services for him. Everyone affected by this tragedy recognized that it might have been avoided if methods of recognizing and including the family in the man's intervention had been possible (Jackson, 2000). 


\section{Current Challenges to Family Practitioners}

During the last two decades, family science has vastly expanded our knowledge base about the reality of family diversity - whether it be based on age, ethnicity, sexual orientation, race, gender, physical or mental ability, rural or urban residence, or income (Gutiérrez \& Lewis, 1999). We have found our existing models of family therapy challenged by these realities, resulting in a need to change the ways in which we view families (Walker, 1993). While a somewhat romanticized notion of returning to "the good old days of family values" has emerged in our country in recent years, the reality is that diverse, multifaceted families have been with us for a long time (Coontz, 2004; Thompson \& Walker, 1995).

To return to the idealized "Leave It to Beaver" conceptualization of families apparent in large numbers only during the 1950s would mean curing HIV/AIDS, providing drug rehabilitation programs for all who need them, refusing to incarcerate mothers, eliminating divorce, restricting the years women are allowed to become pregnant, sterilizing men once they have fathered children with one woman, mandatory permanent placements for children within one year of the death or total incapacity of both biological parents, placing extensive resources into physical and mental health service provision in ways that would vastly expand the tax base of the state and nation, and other solutions that would be considered unfathomable by the majority of citizens of the state. Lest the last challenge seem completely contrived, consider the following examples:

- Parents who are caring for their grandchildren due to the deaths of their children from the HIV/AIDS epidemic still evident among heterosexual adults in the country. It is interesting that the federal government undertook a major study during the last four years to determine whether this phenomenon actually existed because of its implications for custody, health care services, and supervision of the minor children until adulthood (Van Meter \& Hirshorn, 1999; Dannison, Smith, \& Vacha-Haase, 1999).

- Those children who do not have a grandparent generation they can count on, whose parental rights have been terminated, and who languish without adoption in the foster care systems of our state. We have learned that these children, if not adopted within the first 12 to 18 months of their foster care, will simply "age-out" into the adult correctional system (Whiting \& Lee, 2003; Arditti, Lambert-Shute, \& Joest, 2003; Ortega, Guillean, \& Najara, 1996; Wattenberg, 1999). If this happened to only a handful of children, we would as citizens be saddened. That it is now happening to a large number of children is a call to action.

- A growing number of stepfamilies who are managing, minimally, as binuclear families and, maximally, as extended family constellations of biological and fictive kin systems (Ahrons, 2004). Our primary organizations have developed models for serving heterosexual, legally married couples with

Michigan Family Review, 9, 1, 1-10, 2004 (C) Michigan Council on Family Relations 
children. We have not kept programmatic pace with children who may have been socialized by four or six parents over their lives. To whom does the report card go at the end of a marking period? Is the stepfather able to consent to emergency surgery after rushing his stepchild from the soccer game he had been coaching? Is there an Emily Post suggestion for the former spouse's current partner's former spouse at the time of the son's wedding?

- Same sex couples who are facing increasing discrimination in the workplace, unable to participate in decision making for one another because of the lack of a legal relationship. The recent decision in 11 states to penalize the families of same sex couples in terms of workplace benefits raises significant concern for the children in those families. In the past, some same sex couples might arrange to have one partner adopt the other in order to have a legal and binding relationship. Even those possibilities, however, have been closed by our state court system in the last two years (Greene \& Herek, 1994). Family stability is affected by this discrimination which can result in loss of insurance benefits to domestic partners and their children.

- Professional women who have postponed their childbearing until completing their education and/or beginning their careers with vastly different experiences than younger first-time mothers (who are usually studied as part of life span research). How do they face the rituals required of women who have difficulty getting pregnant or maintaining pregnancies while maintaining their employment (McQuillan, Griel, White, \& Jacob, 2003)? How do they juggle a desire for parenting with the realities of the "glass ceiling"? For AfricanAmerican women, this phenomenon is compounded by an inverse relationship between their professional degrees and the probability of ever marrying (ComasDíaz \& Greene, 1994; Gutiérrez \& Lewis, 1999).

- Unwed adolescent mothers who cannot hope to wed their children's fathers because, as we have learned through our research, the fathers are often already married, older males with other children. An abundance of literature indicates that the fathers of women receiving public assistance are seldom in a position to contribute significantly to the economic well being of their children due to their own limited economic and employment opportunities (McClanahan \& Carlson, 2002). Little attention has been paid to the characteristics of the fathers of children born to these women, apart from their earning potential. During the last five years, researchers have identified disparities between teenage mothers' and fathers' ages, although few states attach mandatory statutory rape prosecution for the men who father these babies with minors (Coontz, 2004; Minkler, 2004; Few, Stephens, \& Rouse-Arnett, 2003).

This thematic issue addresses the innovative ways we have begun to allow "current-time" families to inform our practice of human service delivery. It also challenges our traditional method of deriving interventions solely from conceptual 
frameworks about families and the subsequent research to test these frameworks. It is because of this reliance on "expert" knowledge, that we have ignored the rich sources of actual lived experience. Furthermore, the majority of our theoretical models about families are constructed from a model only prevalent during the 1950s (Coontz, 2004; Daly, 2004; Gutiérrez \& Lewis, 1999; Crosbie-Burnett \& Lewis, 1994). The everchanging social and political contexts affecting family life are virtually ignored, and those families not fitting the model are pathologized in our theory, research, and practice. In doing so, we have missed a variety of strengths they exhibit that can inform all families' processes.

\section{An Alternative to the 1950s Model of "The Family"}

Whether practice is engaged in at the individual and dyadic levels or in complex arrays - such as multiple family groups or international family self-help groupsattention to the strengths of families, the contexts in which they live, and a flexible, growing knowledge base of practitioners are critical. Figure 1 illustrates this contextual model.

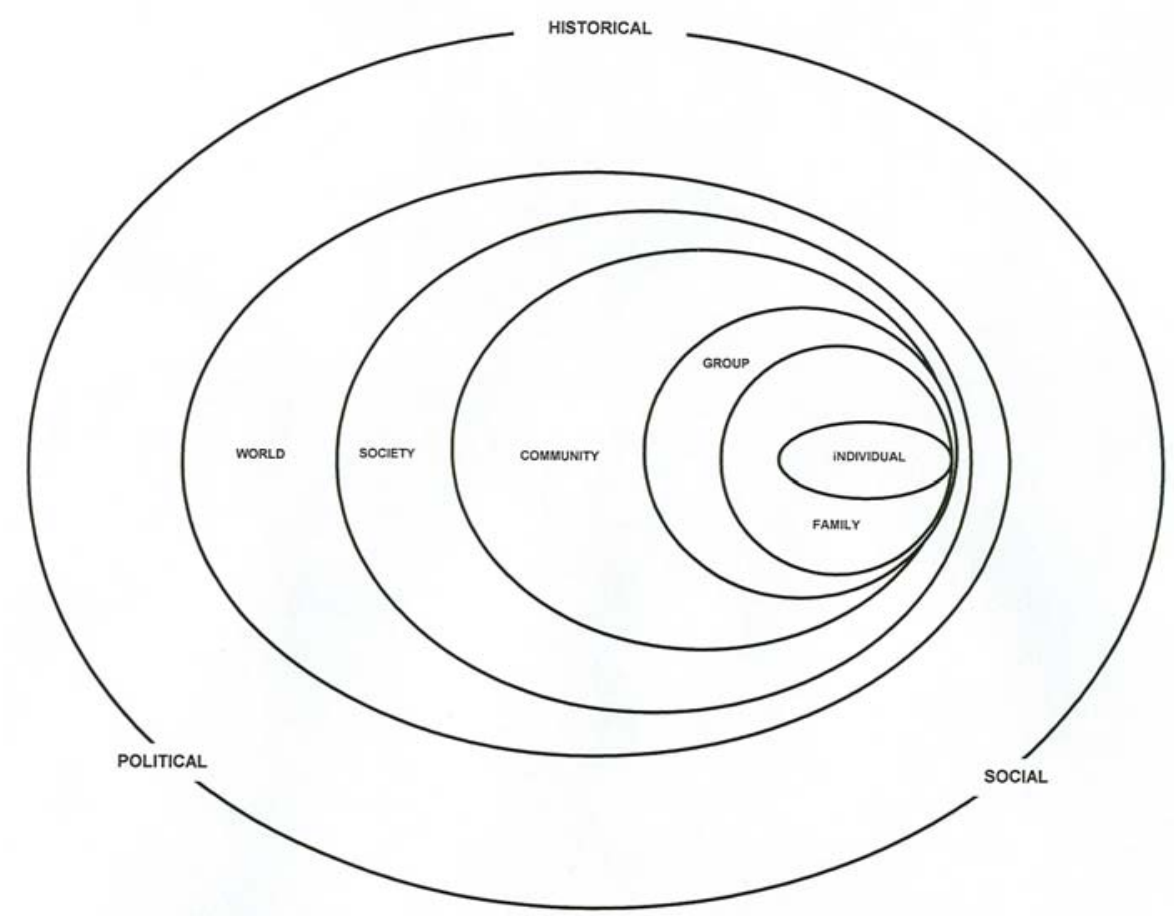

Figure 1: Understanding Familial Contexts

In the contextualized model, individuals and families are understood as parts of communities, the latter with their own set of formal and informal networks. They are also engaged in interaction with the wider society in which they live with its own sets of 
formal networks, such as libraries, schools, mental health centers, churches, and so on (see Billingsley, 1968, for a detailed discussion of these phenomena). As the impact of NAFTA and U.S. interactions with Middle Eastern countries demonstrate, individual, family, group, community, and societal contexts also operate within a global context (Ehrenreich \& Hochschild, 2002). Each of these levels influences and is influenced by the others, and their interaction offers us promise for understanding how to best tailor our interventions.

Locating all of our understanding about families within a social theoretical model prevalent during the 1950s has limited utility for fully understanding modern families; however, the model does demonstrate how important a knowledge of historical, social, and political contexts is for understanding family structures and functioning. For example, WWII and Korean War families benefited from the technological and manufacturing booms following those temporal periods. Social programs were available to veterans of these wars that no longer exist, giving many families the opportunity to purchase homes and educate their own children.

Those social programs were sanctioned by a political world that wanted to welcome men returning from the war and situate them as heads of households. Married women, however, could only obtain credit with their husband's consent during that period, a situation that would be considered politically untenable for women in 2004 . Children born after 1943 and before 1956 have developed their own ways of maintaining and organizing families, given their exposure to the Civil Rights and 1970s Women's Movements, the Vietnam War, and Watergate. Given a larger set of parameters, however, we can expand our knowledge of what works for families by looking at strength-based examples across communities, societies, and the globe, as they are influenced and are influenced by historical, political, and social events.

\section{Innovations in Family Practice: Emphasizing Our Strengths}

The articles in this thematic issue address ways in which historical, political, and social contexts matter. Looking not just at those families meeting the 1950s model of family is the recognition that "one size does not fit all." Many family scholars now propose a model of family practice that integrates family structure with family strengths, resources, and contexts (Coontz, 1999; Jordan, 1997; Lewis \& Gutiérrez, 2003; Suárez \& Lewis, in press). In this issue, strength-based interventions are provided by a range of practitioners working with families, including social workers (see Chavis, this issue), pastoral counselors, medical personnel (see Grinwis, Smith, \& Dannison, this issue), facilitators of self-help groups or multiple family groups (see Song, this issue) or multidisciplinary teams of practitioners and family therapists (see Bishof, Mohr, \& Lieser, this issue).

In Linh Song's article "Rice Paddy to Kung Fool Mask: Race and Cultural Awareness in International and Transracial Adoption Communities" the practitioner is 
viewed as a bridge, uniting disparate viewpoints, equalizing power across relationships, and putting the lived experiences of all parties into their social historical and political contexts. The issue of transracial adoption has been debated across various ethnic and racial groups in this country for almost 40 years. During this time, studies of families who have adopted children from other cultures and countries have steadily increased so that there is now a body of research on the benefits and drawbacks for the adopted children in these families. In her self-reflective article about managing an international transracial adoption internet self-help organization, Song enumerates the concerns raised by this body of research and the continued lack of systematic sources of assistance and support for families who have engaged in transracial adoption.

Song demonstrates the use of a praxis strategy often utilized by practitioners working within an empowerment standpoint (Gutiérrez \& Lewis, 1999). This strategy is composed of informed critical consciousness activities for all parties, using reflection and skill development as capacity building tools to guide action. People are free to ask their questions knowing that they will be treated with respect. People are also allowed to cite unfavorable experiences, knowing that there is someone working with the group who can translate those experiences so that they are heard as systemic rather than individual problems. Song's work also offers recommendations for the ways in which culturally competent family practitioner as collaborator can equalize power differentials among group members and better inform everyday public and private life for transracial adoptees and their families.

Gary Bishof, Laura Mohr, and Monica Lieser's article "Family Therapy Meets Internal Medicine: Innovations in Medical Family Therapy" deals with larger societal and community interactions as it addresses a biopsychosocial perspective in medical family therapy. The authors recognize that family members are more likely to work effectively with family practitioners than with medical personnel and may feel closer to family professionals. When the issues are physical and mental health concerns, this team approach is crucial to ensure compliance with intervention goals and objectives, and improvement for the family system overall. Here, the family practitioner serves as a broker or facilitator so that the strengths of all parties can be integrated into the intervention. Bishof et al. endorse multiple interactions between the therapist and medical personnel as well as with family members, rather than a single staffing meeting. Through these interactions, all parties are able to shape an intervention and understand the nuances that will enhance or deter from its efficacy. The continuing in vivo educational function demonstrates that there is always something new to be learned in the process of working with families.

Bischof and his colleagues also demonstrate how family practice can occur within a hospital setting, offering hope for those families who must make difficult decisions at times when resources for thinking through the consequences of those decisions are not otherwise readily available. Here the family therapist is a broker between the medical personnel and family unit. Secondarily, however, medical family therapists also serve as trainers so that patients effectively utilize their family throughout 
the change/intervention process. Potential exists for the entire family system to participate when the therapist begins with the individual by recognizing that person in a family constellation.

In "Genograms and African American Families: Employing Family Strengths of Spirituality, Religion, and Extended Family Network," Annie McCullough Chavis discusses the innovative adaptation of a tool long-used in family practice: the genogram. The Family Integrated Genogram (FIG) provides a way to assist all engaged in the therapeutic endeavor to begin the intervention identifying the strengths inherent in extended families, including biological and fictive kin networks. The specific incorporation of these kin as parts of the active intervention and the important role of spirituality and religion in the lives of all participants is explored. The FIG's contributions to assisting practitioners in exploring the often overlooked areas of religion and spirituality in the lives of families merit consideration (see Few et al., 2004). The author's contribution of specific questions that family practitioners may use in their social history and FIG assessments is quite valuable.

Barbara Grinwis, Andrea Smith, and Linda Dannison round out this issue with their article on the fears and needs of grandparents parenting grandchildren, "Custodial Grandparent Families: Steps for Developing Responsive Health Care Systems." Filling the roles of coach and educator in this situation, they explicate the current realities of contemporary grandparents: (a) often still employed themselves; (b) not at the generative stage hypothesized as normative for the grandparent population; (c) attempting to deal with their own child who is not able to parent; and (d) potentially having to assist their own aging parents as well. While other articles in this issue also deal with the adult portions of family constellations, Grinwis et al.'s article draws our attention to the ways in which changes in family systems affect children.

Sadly, our social service system is designed such that we are more likely to fund out-of-home placements and ignore the numerous risk factors associated with parenting grandparents. These authors suggest that the emphasis on service expenditures in foster care and adoption rather than extended family placement may be untenable. For Grinwis and her colleagues, family practitioners serve as coaches, providing pertinent information and linking the grandparents with supportive groups and services. Without altering the relationship among those involved in the intervention, family professionals can effectively change the scope of that intervention so that it deals with the social, physical, emotional, and mental needs of both child and grandparent (Van Meter \& Hirshorn, 1999).

In the book review section, the contextual theme of this issue continues as readers are encouraged to consider some of the examples of family practice gleaned from other states and nations. A range of comments on intervention and issue foci are offered by those who have worked intimately within these situations. At the end of this thematic issue are some final comments on family practice: what we know and what we still need to know. 


\section{References}

Kids Count (2003). Data Book 2003. Infants, children and youth with disabilities or special needs. Lansing, MI: Kids Count in Michigan.

Ahrons, C. R. (2004). We're still family. New York: Harper Collins.

Arditti, J. A., Lambert-Shute, J., \& Joest, K. (2003). Saturday morning at the jail: Implications of incarcerated families and children. Family Relations, 52 (3), 195-204.

Billingsley, A. (1968). Black families in White America. Englewood Cliffs, NJ: Prentice Hall.

Comas-Díaz L., \& Greene, B. (Eds.) (1994). Women of color: Integrating ethnic and gender identities in psychotherapy. New York: Guilford.

Coontz, S. (1999). American families: A multicultural reader. New York: Routledge.

Coontz, S. (2004, November). Changing all the rules: The historical transformation of marriage. Paper presented at the National Council on Family Relations Annual Conference, Orlando, FL.

Crosbie-Burnett, M. \& Lewis, E. A. (1993). Use of African-American structures and functioning to address the challenges of European-American post-divorce families. Family Relations, 43 (2), 1-6.

Daly, K. (2003). Family theory versus the theories families live by. Journal of Marriage and Family, 65, 771-784.

Dannison, L. L., Smith, A. B., \& Vacha-Haase, T. (1999). Grandparents as parents: An ecological approach to programming. Michigan Family Review, 4 (1), 37-45.

Danziger, S. K., Ananat, E. O., \& Browning, K. G. (2004). Childcare subsidies and the transition from welfare to work. Family Relations, 53, 219-228.

Ehrenreich, B., \& Hochschild, A. R. (Eds.) (2002). Global woman: Nannies, maids, and sex workers in the new economy. New York: Henry Holt.

Few, A. L., Stephens, D., \& Rouse-Arnett, M. (2003). Sister-to-sister talk: Transcending boundaries and challenges in qualitative research with Black women. Family Relations, 52 (3), 205-215.

Greene, B., \& Herek, G. M. (Eds.) (1994). Lesbian and gay psychology: Theory, research and clinical applications. Thousand Oaks, CA: Sage.

Gutiérrez, L., \& Lewis, E. A. (1999). Empowering women of color. New York: Columbia University Press.

Jackson, R. L. (2001). The clubhouse model: Empowering applications of theory to generalist practice. Belmont, CA: Wadsworth/Thomson Learning.

Michigan Family Review, 9, 1, 1-10, 2004 (C) Michigan Council on Family Relations 
Jordan, J. V. (Ed.) (1997). Women's growth in diversity: More writings from the Stone Center. New York: Guilford.

Lewis, E. A., \& Gutiérrez, L. (2003). Intersections of gender and race in group work. In A. Mullender \& M. B. Cohen (Eds.), Gender and group work. London, UK: Routledge.

London, A. S., Scott, E. K., Edin, K., \& Hunter, V. (2004). Welfare reform, work-family tradeoffs, and child well-being. Family Relations, 53, 148-158.

McQuillan, J., Greil, A. L., White, L., \& Jacob, M. C. (2003). Frustrated fertility: Infertility and psychological distress among women. Journal of Marriage and Family, 65, 1007-1018.

Minkler, M. (Ed.) (2004). Community organizing and community building for health (2 $2^{\text {nd }}$ ed.). New Brunswick, NJ: Rutgers University Press.

Ortega, R., Guillean, C., \& Najara, L. G. (1996). Latinos and child welfare. Prevention Report, 2, 21-23.

Oswald, R. F., \& Culton, L. S. (2003). Under the rainbow: Rural gay life and its relevance for family providers. Family Relations, 52, 72-81.

Rockquemore, K. A., \& Laszloffy, T. A. (2003). Multiple realities: A relational narrative approach in therapy with Black-White mixed-race clients. Family Relation, 52, 119-128.

Suárez, Z., \& Lewis, E. (in press). Spirituality and culturally diverse families. In E. Congress (Ed.), Multicultural perspectives in working with families. New York: Springer.

TBI Challenge (2004). Quarterly publication of the Brain Injury Association of America. Available from http://www.biausa.org/Pages/tbi_challenge_about.html.

Thompson, L., \& Walker, A. J. (1995). The place of feminism in family studies. Journal of Marriage and the Family, 57, 847-865.

Van Meter, M. J. S., \& Hirshorn, B. S. (1999). Grandparents raising grandchildren: Developing self-management. Michigan Family Review, 4 (1) 47-56.

Walker, A. J. (1993). Teaching about race, gender, and class diversity in United States families. Family Relations, 42 (3), 342-350.

Wattenberg, E. (1999). An exchange on juvenile out of home placement: A program evaluation with Joel Alter, Office of the Legislative Auditor. CASCW News (3). Minneapolis, MN: Center for Advanced Studies in Child Welfare.

Whiting, J. B., \& Lee, R. E., III (2003). Voices from the system: A qualitative study of foster children's stories. Family Relations, 52, 288-295.

Zhan, M., \& Pandey, S. (2004). Postsecondary education and economic well-being of single mothers and single fathers. Journal of Marriage and Family, 66, 661-673. 